\title{
On Coloring of Corona Graphs
}

\author{
N. Ramya* \\ Deptartment of Mathematics, Bharath University, Selaiyur, Chennai, India; \\ nramyas@yahoo.com
}

\section{Abstract}

A proper coloring of a graph is an assignment of colors to the vertices of the graph such that adjacent vertices are assigned different colors. A star coloring of a graph $\mathrm{G}$ is a proper coloring such that no path on four vertices is a 2-colored. A coloring of the vertices of graph by K-colors is called acyclic provided that no circuit is bi-chromatic.

In this paper we discuss about the acyclic coloring of corona of $\mathrm{C}_{\mathrm{n}} \odot \mathrm{K}_{1,3}$.

$\mathrm{P}_{\mathrm{n}} \odot \mathrm{K}_{2}$ and star coloring of corona of $\mathrm{P}_{\mathrm{n}} \odot \mathrm{K}_{2}$.

Keywords: Acyclic Coloring, Corona $\mathrm{P}_{\mathrm{n}} \odot \mathrm{K}_{2}$, Proper Coloring Corona of $\mathrm{C}_{\mathrm{n}} \odot \mathrm{K}_{1,3}$, Star Coloring

\section{Introduction}

Let $\mathrm{G}$ be a finite, undirected graph with no loops and multiple edges. The acyclic coloring and star coloring of a graph was introduced by B. Grunbaum in $1973{ }^{1}$.

Chromatic number is denoted $\Psi(\mathrm{G})$. Star chromatic number of a graph $G$ the minimum number of colors which are necessary to star color $\mathrm{G}$. It is denoted by $\Psi_{\mathrm{s}}(\mathrm{G})$. In the following, all the colorings that we will define and use are proper colorings ${ }^{2}$.

Preliminaries and Main Results:

i) Corona of $\mathrm{P}_{\mathrm{n}} \odot \mathrm{K}_{2}$

The Corona graph $\mathrm{G}_{1} \odot \mathrm{G}_{2}$ is obtained by taking one copy of $G_{1}$ of order $P_{1}$ and $P_{1}$ copies of $G_{2}$ and then joining the $\mathrm{i}^{\text {th }}$ vertex of $G_{1}$ to every vertex in the $\mathrm{i}^{\text {th }}$ copy of $G_{2}$. Lt $G_{1}=P_{n}$ be a path graph with $n$ vertices and $G_{2}=K_{2}$ be a complete graph with two vertices. The Corona $G=P_{n} \odot$ $\mathrm{K}_{2}$ is obtained by taking one copy of $\mathrm{P}_{\mathrm{n}}$ of order $\mathrm{n}$ and $\mathrm{n}$ copies of $\mathrm{K}_{2}$ and then joining the $\mathrm{i}^{\text {th }}$ vertex of $\mathrm{P}_{\mathrm{n}}$ to every vertex on the $\mathrm{i}^{\text {th }}$ copy of $\mathrm{K}_{2}{ }^{3}$.

ii) Corona of $\mathrm{C}_{\mathrm{n}} \odot \mathrm{K}_{1,3}$

The graph corona of $\mathrm{C}_{\mathrm{n}}$ and $\mathrm{K}_{1,3}$ is obtained from a cycle $\mathrm{C}_{\mathrm{n}}$ by introducing 3 new pendant edges at each vertex of cycle.

\section{THEOREM (1):}

The graph corona of $\mathrm{C}_{n}$ and $\mathrm{K}_{1}, 3 \mathrm{~V}_{\mathrm{n}} \geq 3$ (when $\mathrm{n}$ is odd) its proper coloring and acyclic coloring are three.

\section{Proof:}

(i) In $\mathrm{C}_{\mathrm{n}}$ coloring has to be given $1,2,3$ periodically.

(ii) For the pendent edges which has attaching with the vertex in cycle, coloring has to be given, Among 1,2,3 the number has not found in the cycle, the rest of the two numbers, among two number's, anyone can be given Eg. $\mathrm{C}_{3} \odot \mathrm{K}_{1,3}$

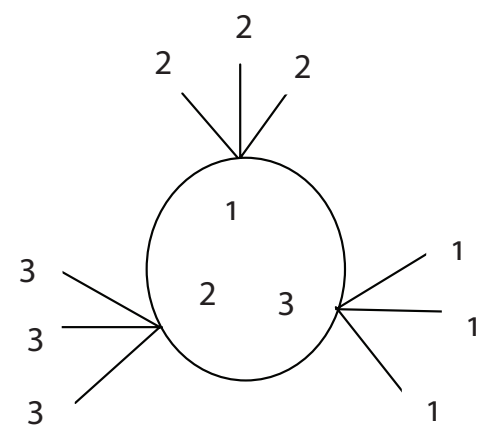

The proper coloring $\Psi(\mathrm{G})$ and acyclic coloring $\Psi \mathrm{a}(\mathrm{G})$ is 3 . 


\section{TheORem(2):}

The graph Corona of $\mathrm{C}_{\mathrm{n}}$ and $\mathrm{K}_{1,3} \mathrm{~V} \mathrm{n} \geq 3$, ( $\mathrm{n}$ is an even) its chromatic number is 2 , and its acyclic chromatic number is 3. (ie) $\Psi(\mathrm{G})<\Psi \mathrm{a}(\mathrm{G})$.

\section{Proof:}

(i) In $C_{n}$ coloring has been given 1,2,3 for the First three vertices. For the Rest of the vertices proper coloring has to be given.

(ii) For the pendant edges which has attaching with the vertex in cycle, coloring has to be given, among 1,2,3 the number has not found in the cycle, the rest of the two numbers, among two numbers any one can be given.

Eg. $\mathrm{C}_{4} \odot \mathrm{K}_{1,3}$

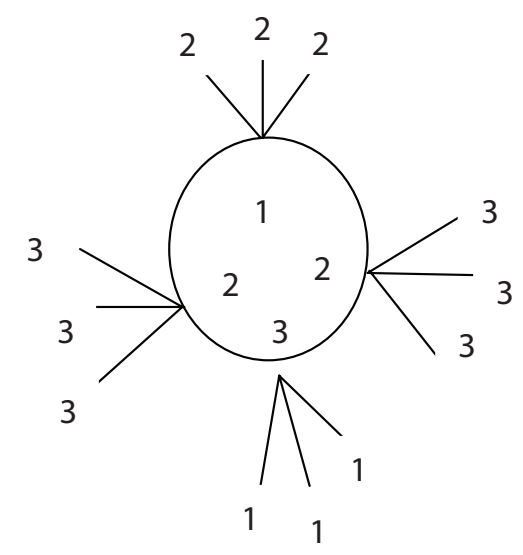

The proper coloring of $\mathrm{C}_{\mathrm{n}} \odot \mathrm{K}_{1,3}$ is 2 .

Eg. $\mathrm{C}_{4} \odot \mathrm{K}_{1,3}$

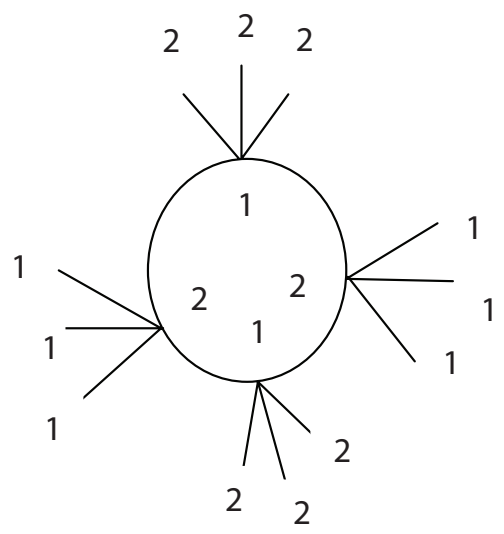

In Corona of $\mathrm{C}_{4} \odot \mathrm{K}_{1,3}$ proper coloring $<$ acyclic coloring.

\section{Theorem (3):}

The graph Corona of $\mathrm{P}_{\mathrm{n}} \odot \mathrm{K}_{2}$ which admits star coloring is 4 and acyclic coloring is 3 .

\section{Proof:}

Let $\mathrm{G}$ denote a graph with vertex set $\mathrm{V}(\mathrm{G})=\mathrm{V}_{1}, \mathrm{~V}_{2} \ldots \ldots \mathrm{V}_{\mathrm{n}}$ The star coloring of this graph defined by
i $\mathrm{f}(\mathrm{u} 1+4 \mathrm{i})=1$
Where $\mathrm{i}=0,1,2,3 \ldots$.
ii) $\mathrm{f}(\mathrm{u} 2+4 \mathrm{i})=2$
Where $\mathrm{i}=0,1,2,3 \ldots$.
iii) $\mathrm{f}(\mathrm{u} 3+4 \mathrm{i})=3$
Where $\mathrm{i}=0,1,2,3 \ldots$
iv) $\mathrm{f}(\mathrm{u} 4 \mathrm{i})=4$
Where $\mathrm{i}=1,2,3 \ldots$.
v) $\mathrm{f}(\mathrm{v} 1+4 \mathrm{i})=3$
Where $\mathrm{i}=0,1,2,3 \ldots$.
vi) $\mathrm{f}(\mathrm{v} 2+4 \mathrm{i})=4$
Where $\mathrm{i}=0,1,2,3 \ldots$.
vii) $\mathrm{f}(\mathrm{v} 3+4 \mathrm{i})=1$
Where $\mathrm{i}=0,1,2,3 \ldots$.
viii) $\mathrm{f}(\mathrm{v} 4 \mathrm{i})=2$
Where $\mathrm{i}=1,2,3 \ldots$.
ix) $f(w 1+4 i)=2$
Where $\mathrm{i}=0,1,2,3 \ldots$
x) $\mathrm{f}(\mathrm{w} 2+4 \mathrm{i})=3$
Where $\mathrm{i}=0,1,2,3 \ldots$.
xi) $f(w 3+4 i)=4$
Where $\mathrm{i}=0,1,2,3 \ldots$.
xii) $\mathrm{f}(\mathrm{w} 4 \mathrm{i})=1$
Where $\mathrm{i}=1,2,3 \ldots$.

Example 1.

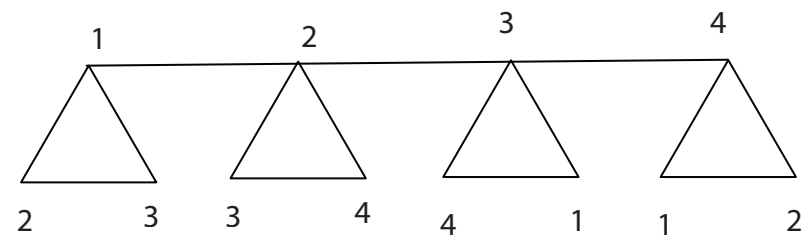

Thus the star coloring of $\mathrm{P}_{\mathrm{n}} \odot \mathrm{K}_{2}$ is 4

Similarly the acyclic coloring of $\mathrm{P}_{\mathrm{n}} \odot \mathrm{K}_{2}$ as follows:
i) $\mathrm{f}(\mathrm{u} 1+3 \mathrm{i})=1$
ii) $\mathrm{f}(\mathrm{u} 2+3 \mathrm{i})=2$
iii) $\mathrm{f}(\mathrm{u} 3 \mathrm{i})=3$
iv) $\mathrm{f}(\mathrm{v} 1+3 \mathrm{i})=2$
v) $\mathrm{f}(\mathrm{v} 2+3 \mathrm{i})=3$
vi) $\mathrm{f}(\mathrm{v} 3 \mathrm{i})=1$
vii) $\mathrm{f}(\mathrm{w} 1+3 \mathrm{i})=3$
viii) $\mathrm{f}(\mathrm{w} 2+3 \mathrm{i})=1$
ix) $\mathrm{f}(\mathrm{w} 3 \mathrm{i})=2$

Where $\mathrm{i}=0,1,2,3 \ldots$.

Where $\mathrm{i}=0,1,2,3 \ldots$.

Where $\mathrm{i}=, 1,2,3 \ldots$.

Where $\mathrm{i}=0,1,2,3 \ldots$.

Where $\mathrm{i}=0,1,2,3 \ldots$.

Where $\mathrm{i}=1,2,3 \ldots$.

Where $\mathrm{i}=0,1,2,3 \ldots$.

Where $\mathrm{i}=0,1,2,3 \ldots$.

Where $\mathrm{i}=1,2,3 \ldots$.

Example 2.

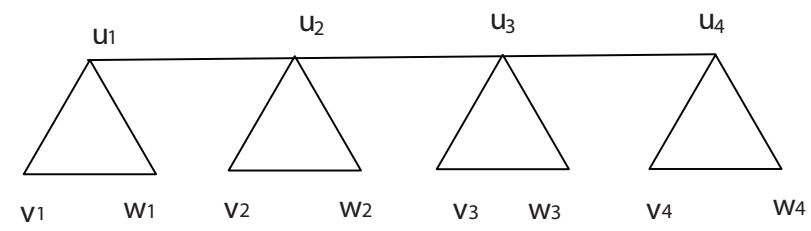

Thus the acyclic coloring of $\mathrm{P}_{\mathrm{n}} \odot \mathrm{K}_{2}$ is 3 .

\section{Conclusion}

Hence we conclude that in the corona graphs $\mathrm{C}_{\mathrm{n}} \odot \mathrm{K}_{1,3}$ has $\Psi(\mathrm{G}) \odot \Psi \mathrm{a}(\mathrm{G})$. Similarly in the corona graph $\mathrm{P}_{\mathrm{n}} \odot \mathrm{K}_{2}$ has, 
$\Psi \mathrm{a}(\mathrm{G}) \odot \Psi \mathrm{s}(\mathrm{G})$.It is of interest to look in to these kind of graphs of harmonious coloring, b-coloring etc.

\section{References}

1. Grunbaum B. Acyclic colorings of planar graphs. Isrel J Math. 1973; 14(3):390-408.
2. Fertin G, Raspaud A, Reed B. Star coloring of graphs. J Graph Theory. 2004; 47(3):163-82.

3. Kaladevi V, Kavitha G. Edge magic graceful labeling of some corona graphs. Proceedings of ICMEB; 2012. p. 77-79.

4. Ramya N, Rangarajan K, Sattanathan R. On rainbow coloring of some classes of graphs. IJCA. 2012 May; 46(18): 36-38. 